Analogue Weather in a Digital World: On the Value of Integrating Both the Physical and the Technological in Day-to-day Experiences of Weather

\author{
Alan E. Stewart \\ College of Education, University of Georgia, Athens, GA \\ Matthew J. Bolton \\ College of Arts and Sciences, Saint Leo University, Saint Leo FL
}

Correspondence for this paper should be addressed to:

\begin{abstract}
Alan E. Stewart, Ph.D.
CHDS - 402 Aderhold Hall

University of Georgia

Athens, Georgia 30602

Email: aeswx@uga.edu
\end{abstract}

Preprinted 2021. 


\begin{abstract}
Smartphones, tablets, and computers offer a wealth of digital information about the world and have transformed the ways we live. Our experiences of the world are now so much more mediated by digital devices than ever before. This is especially the case for living with (and under) the influences of our weather and climate. Here, we explore the idea that an ongoing digitalization of weather and climate, vis-à-vis technology, and the evolving discourse about them may be minimizing or obscuring the actual phenomenological experiencing of weather and climate. We first discuss trends in the digital portrayal of weather and climate and then contrast these with embodied experiences of the weather which, together with "old-school" physical observation techniques, we refer to as an analogue experiencing of the weather. In the third section, we discuss the value of integrating both digitalized and analogue experiences of the weather. Finally, we introduce some ways to become more attuned to the weather of one's place while locating these experiences on the larger landscape of data and digitalized meteorology.
\end{abstract}

Keywords: Climate, Ecological Psychology, Embodied Perception, Emotions, Experience, Smartphones, Weather 


\section{Analogue Weather in a Digital World: On the Value of Integrating Both the Physical and the Technological in Day-to-day Experiences of Weather}

Where is the wisdom we have lost in knowledge?

Where is the knowledge we have lost in information? (Eliot, 1934, p. 7)

Where is the information we have lost in data? ${ }^{1}$

Our globally-connected society increasingly utilizes digital platforms (smartphones, tablets, and computers) to consume weather observations and forecasts, climate outlooks, and news about global climate disruption and change. Cell towers geo-locate many of our devices and can deliver all manner of weather information, including relevant critical watches and warnings, regardless of where we are. We can live-stream video of severe storms and write about weather and climate on social media. Our capability to receive and send detailed meteorological information is unprecedented, although digital weather data and information exists in such abundant supply as to challenge users to understand the most important messages.

Still, our exposure to all this digital potentiality has not been entirely positive. Rather than embrace and integrate digital capabilities to their fullest in the fight on climate change, for example, digital technology has sometimes been used to spread disinformation about the climate and to sow doubt about climate change (e.g., Oreskes \& Conway, 2010; Radin, 2019).

Technology has, in fact, fueled dissent about the role of humans in disturbing the climate and in taking concerted action to mitigate the release of greenhouse gases (e.g., Michaels, 2004; Moran, 2015). Similarly, timely, accurate, and detailed weather warnings delivered to smartphones have not uniformly led to higher levels of compliance with warning messages or their recommendations for sheltering (Stokes \& Senkbeil, 2017; Yoder-Bontrager et al, 2017).

\footnotetext{
${ }^{1}$ We have added a third line to the excerpt from Eliot's (1934, p. 7) opening chorus to The Rock. Our third line was inspired by the information scientist Russell Ackoff, who discussed the organizational hierarchy of data, information, knowledge, and wisdom (Ackoff, 1989).
} 
Sometimes, instead, a digital weather warning functions as an alert to an event so that people go outside to observe it (and perhaps live stream it) rather than shelter from the threat (Harrison et al., 2014; Sherman-Morris \& Brown, 2012).

As the world of weather has become increasingly digital and technological in these and other myriad ways, we have queried the roles and values of an embodied experience of the atmosphere. Within this paper, we would like to consider whether digital media-smartphones, tablets, and computers-for all of their advantages in affording just-in-time information-may be taking us away from an important and primary way of knowing our atmosphere that involves sensing and observing the weather directly. We would like to explore the idea that digitalization of weather and climate, and discourse about them, may be minimizing or obscuring the actual experiencing of weather and climate.

Have we lost something by consuming weather and climate primarily as digital images and words (and words about words and digital images, and so forth)? Recent research suggests so-that, in dis-connecting from nature and opting for digitalization, we are dis-integrating our inner Selves (Fido et al., 2020; Lumber et al., 2018; Pritchard et al., 2020; Richardson et al., 2016; Richardson et al., 2018; Zhang, Piff, et al., 2014; Zhang et al., 2014). In light of this, we first discuss the digital portrayal of weather and then, second, compare this with embodied experiences of the weather which, together with "old-school" physical observing techniques, we refer to as an analogue experiencing of weather. In the third section, we discuss the value of integrating both digital products and one's physical experiences of the weather. Finally, we introduce some ways to become more attuned to the weather of one's place while locating these experiences on the larger landscape of data and digitalized meteorology. 


\section{Digital Offerings of Weather and Climate}

Because of computers, the internet, and the internet of things (IoT) we can digitally observe the weather with a level of precision and accuracy that was impossible even 20 years ago (Benjamin et al., 2018; Stith et al., 2018). Remote-sensing technologies and computer algorithms produce satellite images that allow forecasters to see inside of cloud layers and storms to better understand what is happening in the atmosphere (Ackerman et al., 2018; Mitrescu et al., 2008). The new generation of Doppler radar allows a similar kind of insight within thunderstorms and tornadoes (Wurman et al., 2013). With the computer-based assimilation of these myriad data forms, the accuracy of weather forecasts remains very high within four to six days (Benjamin et al., 2018). This same digital technology has allowed climate scientists the unprecedented capability to monitor the Earth's long-term weather and to model different, possible scenarios that may force the overarching climatic regime to change in different ways.

Regarding the history of these digital capabilities, weather data, maps, and satellite images first became publicly available on the internet in 1993, through the University of Michigan and the University of Illinois (Dougherty, 2017). Before this time, text-based weather information was available online through the University of Michigan beginning in 1991 (Dougherty, 2017). Interactive, online weather information from the U.S. National Weather Service (NWS) first became available in 1995 (https://www.weather.gov/timeline). Although in the mid-1990s it was possible to transmit and retrieve weather information on cellular phones via text messaging, it was not until the advent of the smartphone in 1999 that internet and application capabilities for obtaining and subsequently easily sharing weather information became available (Islam \& Want, 2014; Thurlow \& Poff, 2013). 
A decade ago, only a small minority of weather consumers in the United States obtained their weather information from government or private sources on the Internet, or through the use of smartphones (Lazo et al., 2009). At that time, the primary sources for weather were local or national television stations. Smartphone use, however, has burgeoned since 2009 to become the primary way for people to obtain weather information (Heilig, 2010; Zabini, 2016). A recent study documented that approximately $95 \%$ of a sample of undergraduate millennial students obtained their weather information from a smartphone (Phan et al., 2018).

Alongside and as part of these trends in smartphone use more generally, weather-related smartphone apps have rapidly evolved and proliferated. We counted some 6,000+ weather apps for the Apple iPhone as we prepared this paper, representing a six-fold increase in the roughly 1,000 weather apps that existed in 2009 (Heilig, 2010). An important caveat, however, is that apps may erroneously suggest a greater degree of precision of weather observations or forecasts over an area or time period than is actually possible given the current capabilities (i.e., observation network density and forecast model precision) that exist within atmospheric science (Seim \& Oleksinski, 2015; Zabini, 2016). Other times, weather apps cannot account for smallscale changes that influence their output. For example, an app may pick up on virga (rainfall that evaporates before hitting the ground; generally due to dry air aloft in the upper levels of the atmosphere) and display "rain" as the current condition for a location at which rain is actually not falling. Or, the app may predict heavy snowfall which subsequently doesn't occur due to atmospheric mixing, terrain gradients, or other features undetectable by all but human forecast skill. In other words, the high-tech appearance of many weather apps can imply a greater degree of certainty (or lack of uncertainty) than is warranted (Allenby \& Sarewitz, 2011). 
Social media platforms, most notably Twitter and Facebook, have become forums for disseminating weather information and responding to the aftermath of severe weather events (Ripberger et al., 2014; Silver \& Andrey, 2019; Vos et al., 2018). Approximately 69\% of adults in the US report having used Facebook at least once, while least at least $22 \%$ have used Twitter (Perrin \& Anderson, 2019). A wide range of participants thus post and share their weatherrelated experiences online. At times, such citizen-based science can be helpful (Brandt et al., 2019). At other times, the information may be inaccurate, unreliable, or simply fake (Ali \& Ogie, 2017; Seman, 2020; Spann, 2016). The NWS (https://www.weather.gov/socialmedia) maintains a presence on Facebook and Twitter and many forecast offices also have specific hashtags to vet and curate reports of significant weather events across both sites. The real strengths and benefits of social media seem to accrue in the aftermath of severe or extreme weather events when it is used to coordinate damage reports, communicate needs, and to assist in recovery efforts (Brandt et al., 2019; Knox et al., 2013).

Nevertheless, this digital experiencing of weather is indirect because it is delivered on a two-dimensional plane via a screen (i.e., on a desktop monitor, tablet, or smartphone), and involves immediate access to numbers, maps, or videos with keystrokes or swipes. Weather videos may provide sounds of weather events and also include some narration, but even this experiencing is actually non-experiential. At most, there would be images on a screen and sound from a speaker. Although sight and sounds may be among the most important of the human senses given their role in adaptation (Gibson, 1979/1986), digital platforms do not include a way to connect a person to touch, smell, taste, and to some of the subtler capabilities such as the senses of space and place (Racat \& Capelli, 2020). Moreover, in these virtual experiences, one is missing the emotional connection that is so crucial to a full immersion with the weather (Hinds 
\& Sparks, 2008; Richardson et al., 2016). Thus, there is a difference between the experience of a digital representation of the weather as images and sounds and the embodied visual and auditory perception of that weather as it occurs around someone in time and space (Menary, 2010). This leads to a consideration of the analogue experiencing of weather.

\section{Analogue Experiences of Weather and Climate}

Analogue experiences of weather and climate are those that people have when they are outdoors, within the direct influence of Earth's atmosphere, so that they can sense and observe the weather directly. This is a primary, direct and embodied experience of atmosphere that is not mediated by a digital device (Menary, 2010; Reed, 1996; also see Stewart, 2007; Stewart \& Blau, 2019; and Stewart \& Oh, 2019, for phenomenological discussions on weather and climate as linguistic device and embodied event). Although a person may wear clothing that affords the most comfort given the temperature, may apply a sunscreen if outside in the sun, or may wear a rain coat or use an umbrella if necessary, experiences of the weather directly through the five senses provide not only physical, but affective contact that exceeds what is available digitally.

The ecological psychologist and philosopher Edward Reed (1996, pp. 2-3) maintained that

" $[\mathrm{F}]$ or understanding our place in the world, ecological information is thus primary, processed information secondary. It is this relation between primary and processed experience, in which the balance should be tilted toward primary experience, that has been disrupted and degraded by modern life... It is on firsthand experience - direct contact with things, places, events, and people -that all our knowledge and feeling ultimately rest....there are differences - and real limitations - to indirect experience, to being told about things as opposed to observing them for oneself."2

\footnotetext{
2 Reed's position here aligns with that advocated in an earlier era by Austrian psychologist Alfred Adler (1956, p. 116) who emphasized active experiencing and behavior: "Trust only movement. Life happens at the level of events, not of words. Trust movement."
} 
Our human ancestors relied upon their senses to discern the weather and to foretell its tendencies. There is something sacred and mysterious about the air and its winds-it brings life and a certain, pronounced awareness (Abram, 1996). Within some cultures, people use a close reading of the skies and seasonal (phenological) changes in flora and fauna to determine the opportune timing of planting and harvesting (e.g., Anandaraja et al., 2008; Garay-Barayazarra \& Puri, 2011). Similarly, phenological information and accumulated experiences of past weather help Indigenous peoples to predict wet or dry periods (Gearheard et al., 2010; Pennesi et al., 2012; Roncoli et al., 2002). With the onset of global climate change disrupting Earth's weather patterns, however, meteorologists and government officials are beginning to assist people in some of these cultures; for example, in Burkina Faso to incorporate seasonal forecasts into agricultural planning and practices (Roncoli et al., 2002).

A rich heritage of weather wisdom steeped in direct observation and sensing emerged within North America in the era leading up to the 20 th century (Dexter, 1904; Garriott, 1903). Typically, this wisdom was developed for a place and described as a sequence of elemental occurrences. An example for Atlanta, Georgia is:

"The general conditions which precede frost are high or rising barometer, temperature 55 and below, low humidity, light to fresh winds, usually from the west to north, and clear or clearing weather." (Garriott, 1903, p. 52).

Sometimes, weather relations were phrased in conditional statements, such as this observation offered by Luke Howard: "If cirrus clouds form in fine weather with a falling barometer, it is almost sure to rain." (Garriott, 1903 p. 12). People similarly evaluated the airs and waters of places, along with prevailing winds and seasonal changes, to find the most desirable places to build a home (Valenčius, 2002). The development of a sense of the weather and what it may bring was considered an important life skill for people up to the mid- $20^{\text {th }}$ 
century. Psychologist Granville Stanley Hall (1893) discussed the content of children's knowledge about weather and their use of it for practical purposes.

The use of synoptic meteorology techniques in the early days of modern weather forecasting, which involved sending surface observations to a central location so that maps could be drawn and the movement of weather fronts extrapolated, began formally only around 1919 (Benjamin et al., 2018). Prior to this time, which saw the advent of polar front theory (e.g., Bjerknes, 1921; see http://www.eumetrain.org/satmanu/polar_front_theory/index.html) and other theoretical advances, forecasting the weather of a place depended upon an acute observation of the present weather conditions and observation of the clouds and their movements.

It was through this type of systematic observation and inference that Luke Howard first studied and categorized clouds in 1865 . Weather forecasters have continued to utilize an analogue approach rooted in sensing and direct observation to supplement more technological and digitalized advances in forecasting. Observational heuristics in which one searches weather records and his or her memories for similarities to the current or preceding weather from known, past cases of weather are common (Doswell, 1986, 2004; Toth, 1989). An early exemplar of this analogue approach, which persists to this day, was Garriott's (1897) wind-barometer table. Here, a forecast could be developed from single-place observations involving the use of the present wind direction and the barometric pressure tendency.

For example, if the winds were southeasterly and the pressure was falling towards 29.80 inches, then one could expect clouds and rain within 18 hours and continuing for a day or two (Garriott, 1897; note, he applied these observations to the middle and upper Mississippi and lower Missouri, and the Ohio, River Valleys and the Mid-Atlantic and New England regions). U.S. Weather Bureau meteorologists of the late 1800s and early 1900s employed such analogues 
and heuristics along with their localized knowledge to create forecasts. "Decision-tree" conceptual forecasting models based on these principles were later developed (e.g., Colquhoun, 1987; Smigielski \& Mogil, 1995; Olander \& Velden, 2007; Velden et al., 2006). With its grounding in the long-term climatological observations of weather systems across North America, people can still use the wind-barometer method to make general weather predictions in mid-latitude regions (Hubbard, 2000). In summary, the weather itself is a medium for communicating the atmosphere's present and possible future states (Peters, 2016; Randerson, 2018).

\section{Emotional Significance of Sensing the Weather}

Our human ancestors adapted to the weather and climate of their locales by sensing and observing the atmospheric events that occurred (Hetherington \& Reid, 2010). A key characteristic of adaptation for both humans and animals consists of using multiple senses in uncertain environments and then integrating the information into perceptions (Deroy et al., 2016; Munoz \& Blumstein, 2012; Tsakiris, 2017; Wallace et al., 2020). This process allows the person or animal to determine the event(s) that most likely produced what was detected in the environment (Jensen et al., 2020; Kersten et al., 2004).

The use of multisensory perception for survival also involves the emotional system, especially when an event may be hazardous (Markowitsch \& Staniloiu, 2011). Although the sense of sight may be a primary modality (Hutmacher, 2019), sounds and smells also provide adaptive information that may give rise to emotional experiences (e. g., of alarm, fear, anger). Smell may elicit emotions and also cue memories of past experiences (e. g., the smell of a spring rain amid blooming flowers cues memories of past spring times; Markowitsch \& Staniloiu, 2011; Willander \& Larsson, 2007). Similarly, changes in the loudness and pitch of natural sounds like 
rainfall induce changes in human emotions (Frühholz et al., 2016; Ma \& Thompson, 2015). The coordination of sensory information and its relationships with emotional processes occurs in the insular cortex and the amygdala, two sub-cortical structures that also process cognitive anticipations of events (Moraga-Amaro \& Stehberg, 2012).

Thus, humans have come to rely on a multisensory array that tends to operate quickly and somewhat automatically to render adaptive predictions about the environment (Kahneman, 2011; Kelly, 1955). In this way, the weather and climate contribute to the affective atmosphere of a place. Along with other features, the weather provides an affective background (or foreground) for human activities (Gannon, 2016; Hall \& Endfield, 2016; Robertson, 2015; Vannini et al., 2012). In this regard, it is interesting to consider that although textual or graphic-based weather warnings are meant to warn of impending danger, the two-dimensional and primarily visual nature of these messages may not be able to achieve the desired emotional effect because they do not leverage the arousal capabilities of other human sensory channels.

We have explored the extent to which people sense and observe the weather, report being emotionally affected by the weather and seek information and knowledge about the weather (Bolton et al., 2020; Bolton et al., 2021; Stewart, 2009; Stewart et al, 2012). Weather salience encompasses the ways in which people find the weather to be psychologically significant. The facets of weather salience are related, in that people who sense and observe the weather usually also seek information about it and think about the weather. These individuals also describe being emotionally affected by the weather and forming attachments to the weather patterns of their places. Importantly, people who have had a significant interaction with the weather-a severe storm that resulted in damages or memorable event like a holiday snow storm, for examplereported overall greater weather salience. Weather salience is associated with placing greater 
value on weather information and forecasts (Stewart et al., 2012) and may be related to cognitive attention processes that lend themselves to its increase or decrease (Bolton, Blumberg et al., 2020; Bolton et al., 2020). Snow, because of its ability to dramatically alter the landscape and thus potentially disrupt the rhythm of everyday life, possesses a unique potential for engaging the mind and body (Hall \& Endfield, 2016; Mergen, 1997). Minor weather events like a steady rain or fog may for some people hold a similar potential (Gannon, 2016).

Although weather salience as a set of traits or characteristics has its focus on what is within the person, ecological psychologists have gone further to, in Mace's words "ask not what is inside the head but what is the head inside of" (1977, p. 43). Ecological psychologists have posited that rather than being passive receivers of environmental stimulation, people are active perceivers and actors within the moment (Gibson, 1979/1986; Putnam, 1995; Reed, 1996). The world as each person experiences it is subjective; each person is the organizer, constructor, and sole authority of any sensations, perceptions, or feelings that come into awareness, and of responses which are acted out in the world (Fivush, 2001; Gibson, 1979/1986; Merrill, 1991; Mix, 2006; Polanyi, 2015; Putnam, 1995; Quade, 2007; Reed, 1996; Rogers, 1995). From human developmental perspectives of the Self (the "I-language," percept orientation work of John and Joyce Weir, for example; see Merrill, 1991; Mix, 2006; Quade, 2007), one can understand that while people may have weather knowledge or familiarity within their memories or on their digital screens, it is what is seen, felt, smelled, heard, or tasted at the precipice of moment-tomoment action potential which constitutes the information the person uses to behave in that instant.

Percept orientation recognizes that " $I$, as an individual, construct reality and my place in the world" and provides a language to express oneself within the present moment of this reality. 
To the extent the person perceives things in the world, those things are embedded and subsumed within the individual's personhood; the individual is that which is perceived (e.g., Mix, 2006;

Quade, 2007; Rogers, 1995). Such embeddedness-especially within the weather-encompasses a personalized knowing-how and knowing-when which differs from knowing-that.

\section{Towards Both the Analogue and the Digital}

Our position is that the abundant supply of on-demand digital weather data and information risks obviating a more personal engagement with the weather-of discarding some felt-sense aspects (Gendlin, 1982) of weather that could deeply inform one's intuitive meteorological understanding. We advocate a middle path in which the individual "focuses" inwards and asks of themselves what it is in all that about the weather they can grasp (Gendlin, 1982). Those aspects of the weather which resonate with the individual will rise to the surface during this meditation-like process, and can then serve as points of analogue experiencing to be subsequently foregrounded in the wealth of digital weather data. To engage in and cultivate this process, one may do the following, following from and based on the ideas of Eugene Gendlin:

1. First, clear a mental space for yourself. Imagine yourself taking an assortment of storage boxes strewn about a room in your home and setting them all to one side. Stack them up and place them so that you have some space in the room. This is what you will do with whatever is on your mind when you want to go into this process of focusing. Just set it aside.

2. Close your eyes and narrow your attention; concentrate your awareness inside of you. You might place a hand on your stomach to help center on your bodily sensations. Make an effort to notice your breath and the rise and fall of your abdomen with it, and 
then take a moment to just be. Become aware of how you are feeling inside, in the moment. This often takes practice at first.

3. Ask yourself, "what is it about the weather, what is it in all that about the weather, that I can grasp within my awareness?" Sit with this question for a few minutes, and see what arises within you based on what you know of the day's conditions. You should get a vague feeling at the edge of your awareness. Stay with it as best you can.

4. When you notice this feeling, ask it about its nature and then pause to reflect on the weather conditions that are occurring at your place when doing this exercise. Is it hot? Cold? Is the air thick with humidity? Is there significant cloudiness (and so on)? As you reflect, try to get a sense of whether the particular weather element you are pondering matches the feeling inside you. Eventually, you should feel a pull or attraction, something shifting inside of you that fits and feels right, matching with the weather element (the heat, cold, cloudiness, etc.) upon which you reflected. This is the aspect of the weather that resonates with you in that moment, and is the one you should thereafter endeavor to experience that day.

To illustrate, one might, as a first step, focus inwards and get a felt, bodily sense that the clouds of the particular day are especially interesting, and begin paying them keen attention-watchful for

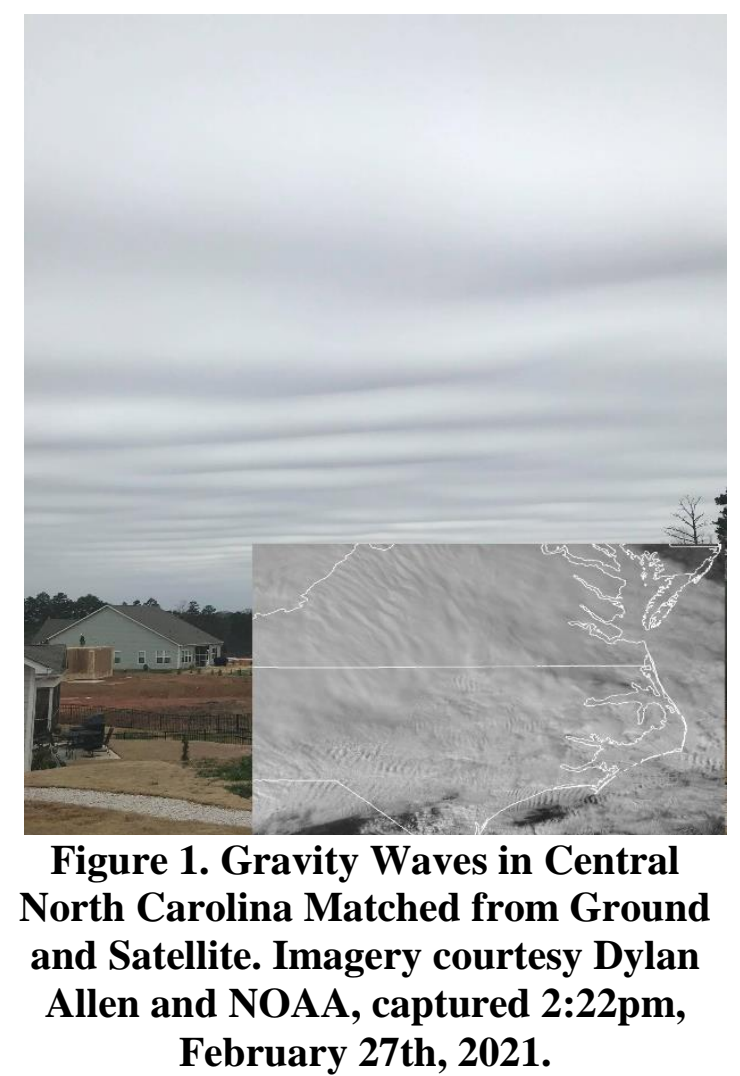


small structural changes or even just general patterns of motion or formation. One might then, in a second step, locate these same clouds on visible satellite imagery and match their observational direction with the orientation of the clouds on satellite (as demonstrated in Figure 1 above).

If it is temperature or humidity that resonates, one might go outside and simply endeavor to notice and savor the sensations those conditions evoke inside. These particular weather elements may elicit discomfort, but we can foster within ourselves an appreciation for them in this way. These sense-based experiences can then be linked to digitized weather by subsequently retrieving a local surface weather map, finding your nearest observing station, and taking note of the latest conditions (see https://www.weather.gov/jetstream/wxmaps_max for interpretation guidance; Figure 2). Eventually, focusing will not be needed for this activity; you will just fall into it naturally. A benefit of such a both-and approach is that it builds a person's relationship with the immediate, experienced atmosphere and wider natural environment-a bond between the knower and the known is nurtured (Barbaro \& Pickett, 2016; Huppertz \& Schatanek, 2017).

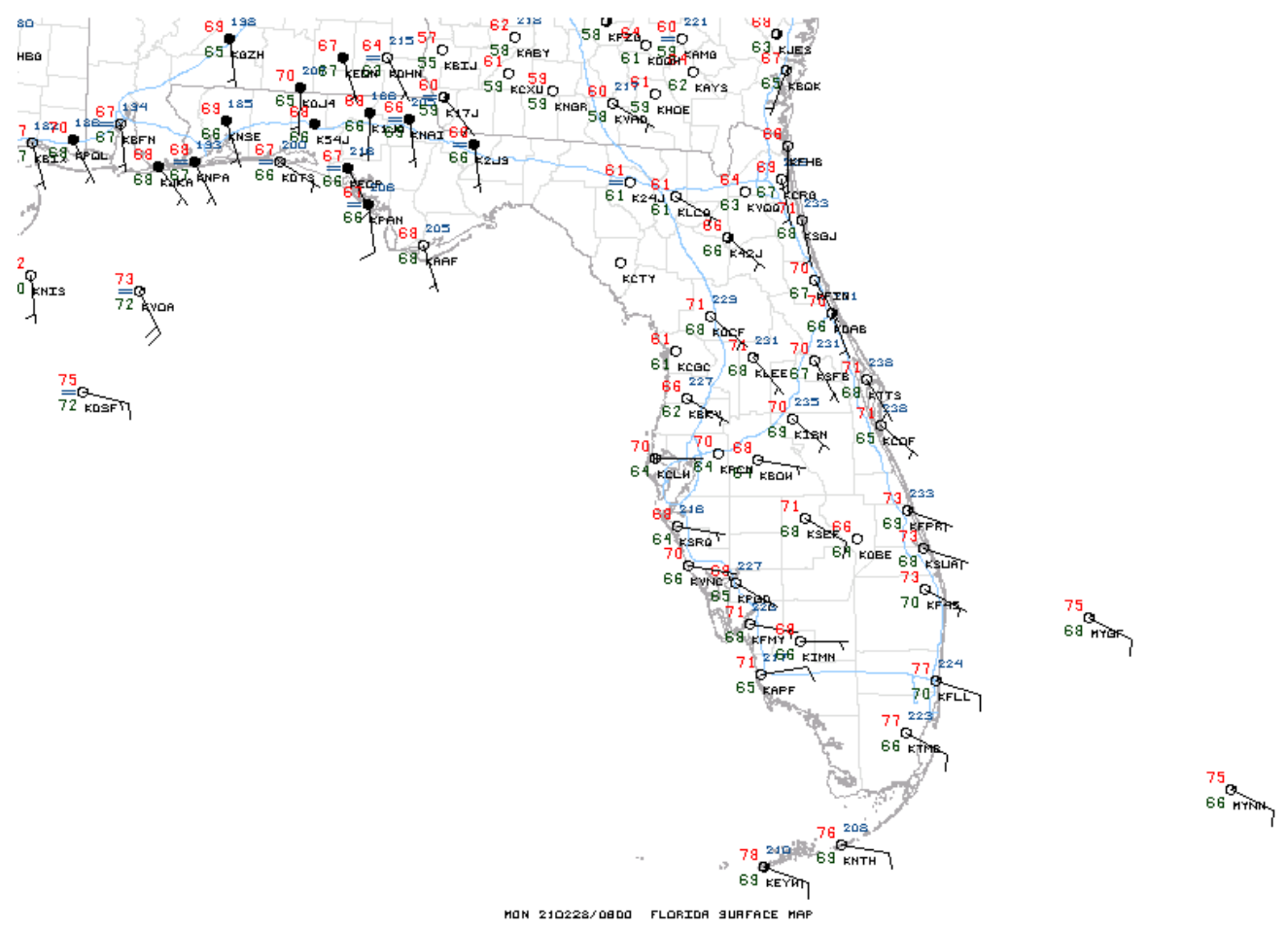


Figure 2. A Florida-based surface weather map for 1am EST, February 28th, 2021

Another strength is that physical, sensory-based attention to local conditions and to the digital portrayal of these conditions gives rise to thinking and problem-solving about how the two sources of weather-knowing are related-at least when they are consistent, and especially when they may be discrepant. Meteorologist Mike Mogil (2011/2020) maintains that people can be "observationalists" who constantly query their surroundings to identify patterns in the world. Importantly, observationalists question not just what fits in a scene, or in data, but also what does not fit. This can be compared to the if-then, rule-based concept of systemizing, especially in a meteorological context (Bolton, Blumberg et al., 2020; Bolton et al., 2020).

\section{Behavioral Recommendations to Foster Weather-Climate Immersion and Connection}

What could be done to strike a greater balance between analogue and digital experiences of weather? Because digitized weather and climate information is now ubiquitous, we emphasize cultivating an analogue, observation- and sensory-rooted sense of the weather and workably fitting it to a digital background. The suggestions we offer are in the form of behavioral recommendations to implement outright and then work towards. The goal of these strategies is to behave one's way into new ways of thinking about, feeling, and relating to the weather and climate-to have experiences that invite the creation of new meanings and novel modes of being with the atmosphere and its digital representations (Kelly, 1955; Gendlin, 1997).

First, spend time outside in a place that affords a good view of both the sky and the land. Devote your time to just being outside and not working or playing. Experience what the landscape and skyscape have to offer in their entirety (Hamblyn, 2017; Pretor-Pinney, 2006; Robertson, 2015). Set a deliberate intention to attend to the sensations arising within you in response to the events of the outdoor environment. If you are walking, take care to mindfully notice the rising, falling, and swirling motions of air created by your arms swinging at your 
sides. Notice the air flowing past your face in the form of blowing wind. Look to the sky and hold witness to the clouds (or lack of clouds) above you (and see https://www.weather.gov/jetstream/basicten for identification basics). Concentrate your attention on the feel of the sun's rays or the air's coolness on your skin. What emotions and physical feelings do these various sensations evoke within you?

Do this several times during your favorite and least favorite seasons of the year. What types of weather do you observe during these two seasons? Can you become more tolerant towards types of weather you would normally find unpleasant; can you come to accept them via a certain stance of appreciation, recognizing that your unique and subjective moment-to-moment experience of that type of weather is passing instantaneously and will never to be felt in quite that same way again? Compare the cloud colors and shapes that you see across the two seasons you choose. Take photos of the skyscape, and watch for the play of shadows cast upon the ground by any trees around you.

Take note of how the sun's angle affects your perception of the clouds-their color, shape, and so forth-and any shadows you observe. What does the air feel like; can you sense a certain heaviness or crispness to it? What about the wind, and how does the air smell? Pay attention to how you feel, both inside and out, when doing this exercise. What about particular weather conditions makes you feel emotionally good or bad? Write a description of the weather that occurs in your least favorite season, and consider: Is there a message in this weather for you? Take photos of the current cloud cover and then match this "ground truth" observation with realtime satellite imagery. Consider sharing your reflections and any images you might digitally photograph and/or collect online on social media. 
Second, record the feelings you have during different kinds of weather. Some people report heightened emotional sensitivity to changes in the daily weather. Generally, people with such sensitivity report feeling better emotionally on sunny, fair days and have a tough time getting going and feeling well on overcast, rainy, and cold days; for some people the opposite occurs. For one week during each month of the year, record how you feel emotionally at the start of each day and the weather that was occurring at that time. After recording for a couple of weeks, do you notice any patterns? Again, for weather that had a strong effect on you, was there a message in the type of weather for you? Can you find others with a similar sensitivity to the weather among those in your social media network?

Third, become a weather observer and share your data (Burt, 2012; Pretor-Pinney, 2006). The Community Collaborative Rain, Hail and Snow (CoCoRaHS; http://www.cocorahs.org) network exemplifies citizen science. Since 1998, CoCoRaHS has grown to a network of more than 27,000 active observers in the United States, Canada, Puerto Rico, the Bahamas, and the U.S. Virgin Islands who invest in a roughly $\$ 40.00$ (USD) rain gauge and who read and report their rainfall online every morning (usually at 7am local time). The government weather services rely upon CoCoRaHS measurements because they provide a much finer resolution of the rain or snow that may have fallen over an area not covered by the weather service. Television meteorologists use the observational network to supplement their own and government data displayed in on-air weather communications. The data are open and free to everyone to view. Peoples' comments about the weather of their place are especially informative because the descriptions are usually in plain, everyday language.

Alternatively, consider setting up a more complete weather station at home so that in addition to CoCoRaHS measurements you go outside and observe the type and amount of cloud cover, 
read the temperature and humidity, along with the wind speed and direction. Buy a barometer and keep track of the air pressure. There is a wide variety of different kinds of weather station instruments to fit almost any budget (Burt, 2012), and these include automated solutions as well. But in this exercise, consider especially the kinds of instruments that take you outside and into the weather, to physically read analogue instruments and to get an observational sense of what the weather is doing. Record your observations and then post them online at a citizen science website like Weather Underground (http://www.weatherunderground.com) or the United Kingdom Weather Network (https://www.ukwx.net/wxlinks.php). Finally, the NWS provides storm spotter training for individuals either interested in learning about the science of severe weather or interested in assisting with the reporting of severe weather (https://training.weather.gov/wxspot.php).

Keeping track of the weather in these ways performs a community service and can be educational. Records of weather at your place allow you some empirical data for use in tracking the trends and the variability of the weather, and in fine-tuning your intuitive perceptions of weather in your place. If you are asked whether the weather of the season is colder or warmer than last year, for example, you have the data that will let you speak beyond an opinion, impression, or memory. Compare your station's readings with those of other observers and with the weather service. Consider what may make your readings similar to or different from those of nearby stations and try to solve this problem.

Do you live on a hill, where you are somewhat more exposed? Alternatively, do you live in a shady hollow or frost pocket such that you are always a few degrees cooler than surrounding places? Is a large body of water nearby which could mediate or moderate temperatures in its vicinity, or even affect sea and land breeze interactions and storm outflow patterns? Do you live 
in or near a city whose urban heat island may modify the conditions relative to nearby locations that are more rural? Investigating these questions will help you to appreciate how locationsensitive the weather can be (which relates to the discipline of micrometeorology). It will also help you to understand one of the most important and often overlooked rules of the weather-that it can vary quite a bit between two geographically-close locations.

Fourth, and finally, try your hand at predicting the weather of your local area. You do not need an automated weather station to do this, but one-or even just a simple analogue thermometer, barometer, and anemometer setup-can be a big help. With knowledge of the barometric pressure and known or estimated wind direction at your location, try to use the windbarometer table to predict your weather. Use some of the wide assortment of available surface and upper-air weather maps (e.g., https://www.wpc.ncep.noaa.gov/\#page=ovw) to examine weather fronts and then use these along with your personal weather readings and interpretationsrecord short notes with your data reports, and describe the weather conditions at the time-to make your forecasts.

Alternatively, try using the knowledge of your location along with your readings to tweak or adjust the forecast you receive from a central weather office. Consider, for example, some of the features mentioned in the last paragraph (hills, valleys, etc.) See how you do making your own forecasts based upon these experiences. As you begin to establish a climatological record at your place, can you see the human element inherent to the process of creating your forecast (Doswell, 1986, 2004; Hoffman et al, 2017)? This kind of involvement with the weatherespecially if people ask for your forecasts, or about your longer-term records-builds an investment in the weather and promotes a deeper understanding of it. This investment can go far 
beyond just a two-dimensional, digital consumption of a news story about the weather followed by a posting or tweet about it.

\section{Conclusions}

The benefit of an analogue emphasis of the weather comes from what it can uniquely provide at this time, when the Earth's climate is becoming progressively more disturbed by human activities. If we immerse ourselves in the weather-in the atmosphere-we will sense and observe its behavior. If we do this over time, we will involve more of our psychological processes and develop a relationship with the weather of the places we inhabit. We likely will become attached emotionally to our weather, beyond a passive-receptive type of relationshipone in which the weather acts and people reflexively react. This may in turn foster an enhanced protective action response to severe and dangerous weather of our respective places and provide a template by which others can take protective actions themselves.

But beyond the fostering of protective actions, we advocate for a deeper and more sensual attachment to, and with, the weather (Abram, 1996; Vannini, et al., 2012). This analogue relationship is not just one in which we measure the weather to predict its behavior for the planning or enabling of activities. Rather, it involves weather attunement and deep listening to the messages of the atmosphere, which we incorporate into our personal meaning-making perceptual systems in order to achieve a deeper connection with the natural world around us. From the ordinary to more extreme weather events, what might the weather and climate be trying to convey to us from day-to-day?

Might a span of rainy or snowy days be the weather's way of telling us to take a break from traveling, producing, consuming, and polluting as usual? Could the atmosphere's message here be not to fight, transcend, or dominate the elements but to give ourselves and the 
atmosphere a break from always going and busying ourselves? At this level of attunement, we are part of the weather-the weather is in us and we are in the weather. By mindfully attending to the weather, we are taking care of ourselves. Relating, in this manner, to the weather can build concern and commitment towards taking action to help the climate (Barbaro \& Pickett, 2016). Additionally, a more sensual relationship with the weather may enhance our sense of inclusion and connection with nature overall (Huppertz \& Schatanek, 2017; Mayer \& Franz, 2004; Shultz, 2002; Tuan, 1974).

Our emphasis on the analogue experiencing of weather may come across as romanticized, particularly at a time in human history when society has so many new digital weather capabilities that are rapidly evolving. Still, it is important to remember that our ordinary sensory modalities for experiencing the weather have existed for a long time. As an illustration, if we take the emergence of Homo Sapiens some 200,000 years ago to have occurred at midnight and it now is 8am, we have had digital technology for only the last five seconds. In other words, we have a long history of relying upon our human sensory capabilities to experience the variability in weather and climate and comparatively little experience in integrating the benefits of digital information into our lives.

Perhaps it is because we have become so perceptually-attuned to weather over our human history that we have come to take our animated experiences of it for granted. The weather is oldfamiliar-and has always been there, but digital technology is new and captivating. Through it we can experience the weather and climates of places that we have never visited. It is important to remember, however, that the representation of things is not the things themselves; the map is not the territory (Korzybski, 1958). We will maximize all the potential benefits of digital weather technologies when we use them to supplement our embodied experiences of the atmosphere. 


\section{Acknowledgements}

AES conceived the paper and both authors contributed equally to authorship. MJB was supported academically during the period of this work by a Graduate Fellowship sponsored by the U.S. National Weather Service and awarded by the American Meteorological Society. The opinions, conclusions, and recommendations expressed here are those of the authors and do not necessarily reflect the views of the National Weather Service or American Meteorological Society. We are grateful to Dylan Allen for permission to use his photo and to Patrick Howley for helpful feedback regarding the work of John and Joyce Weir and Eugene Gendlin. 


\section{References}

Abram, D. (1996). The spell of the sensuous. Vintage Books.

Ackerman, S. A., Platnick, S., Bhartia, P. K., Duncan, B., L’Ecuyer, T., Heidinger, A., Skofronick-Jackson, G., Loeb, N., Schmit, T., \& Smith, N. (2018). Satellites see the world's atmosphere. Meteorological Monographs, 59, 4.1-4.53. https://doi.org/10.1175/amsmonographs-d-18-0009.1

Ackoff, R. L. (1989). From data to wisdom. Journal of Applied Systems Analysis, 16, 3-9.

Ali, A., \& Ogie, R. (2017). Social media and disasters: Highlighting some wicked problems [Leading Edge]. IEEE Technology and Society Magazine, 36(4), 41-43. https://doi.org/10.1109/MTS.2017.2763450

Allenby, R. B. \& Sarewtiz, D. (2011). The techno-human condition. Massachusetts Institute of Technology.

Anandaraja, N., Rathakrishnan, T., Ramasubramanian, M., Saravanan, P., \&Suganthi, N. S. (2008). Indigenous weather and forecast practices of Coimbatore district farmers of Tamil Nadu. Indian Journal of Traditional Knowledge, 7(4), 630-633.

Barbaro, N., \& Pickett, S. M. (2016). Mindfully green: Examining the effect of connectedness to nature on the relationship between mindfulness and engagement in pro-environmental behavior. Personality and Individual Differences, 93, 137-142. https://doi.org/10.1016/j.paid.2015.05.026.

Benjamin, S.G., Brown, J. M., Brunet, G., Lynch, P., Saito, K. and Schlatter, T. W. (2018). 100 years of progress in forecasting and NWP applications. Meteorological 
Monographs, 59, 13.1-13.67. https://doi.org/10.1175/AMSMONOGRAPHS-D-18-

$\underline{0020.1}$

Bjerknes, V. (1921). On the dynamics of the circular vortex: With applications to the atmosphere and atmospheric vortex and wave motions. Geofysiske Publikationer, 2(4).

Bolton, M. J., Blumberg, W. G., Ault, L. K, Mogil, H. M., \& Hanes, S. H. (2020). Initial evidence for increased weather salience in autism spectrum conditions. Weather, Climate, and Society, 12(2), 293-307. https://doi.org/10.1175/WCAS-D-18-0100.1

Bolton, M. J., Mogil, H. M., \& Ault, L. K. (2020). An exploratory, preliminary report on United States weather education trends and general population links between weather salience and systemizing. Journal of Operational Meteorology, 8(4), 54-63. https://doi.org/10.15191/nwajom.2020.0804

Bolton, M. J., Allen, D. R., Ault, L. K., Burton, K., \& Mogil, H. M. (2021). Measuring epistemic weather curiosity: Initial validation of an individual difference questionnaire. PsyArxiv, preprint. https://doi.org/10.31234/osf.io/pv6ar

Brandt, H. M., Turner-McGrievy, G., Friedman, D. B., Gentile, D., Schrock, C., Thomas, T., \& West, D. (2019). Examining the role of Twitter in response and recovery during and after historic flooding in South Carolina. Journal of Public Health Management and Practice, 5, E6-E12. https://doi.org/10.1097/PHH.0000000000000841

Burt, S. (2012). The weather observer's handbook. Cambridge University Press.

Colquhoun, J. R. (1987). A decision tree method of forecasting thunderstorms, severe thunderstorms and tornadoes. Weather and Forecasting, 2, 337-345. 
Deroy O, Spence C, Noppeney U. (2016). Metacognition in multisensory perception. Trends in Cognitive Sciences, 20(10), 736-747. https://doi.org/10.1016/j.tics.2016.08.006

Dexter, E. G. (1904). Weather influences. MacMillan Company.

Doswell, C. A. (1986). The human element in weather forecasting. National Weather Digest, 11(2), 6-17. http://www.flame.org/ cdoswell/publications/Human/Human_Element.html

Doswell, C. A. (2004). Weather forecasting by humans-Heuristics and decision making. Weather and Forecasting, 19(6), 1115-1126. https://doi.org/10.1175/waf-821.1

Dougherty, E. (2017, February 16). Wunderground.com: Democratizing weather. The Michigan Engineer News Center. Retrieved January 16, 2020 from https://news.engin.umich.edu/2017/02/wunderground/

Eliot, T. S. (1934). The rock: A pageant play. Faber \& Faber.

Fido, D., Rees, A., Clarke, P., Petronzi, D., \& Richardson, M. (2020). Examining the connection between nature connectedness and dark personality. Journal of Environmental Psychology, 72, 101499. https://doi.org/10.1016/j.jenvp.2020.101499

Fivush, R. (2001). Owning experience: Developing subjective perspective in autobiographical narratives. In C. Moore \& K. Lemmon (Eds.), The self in time: Developmental perspectives (p. 35-52). Lawrence Erlbaum Associates Publishers.

Frühholz, S., Trost, W., \& Kotz, S. A. (2016). The sound of emotions-towards a unifying neural network perspective of affective sound processing. Neuroscience and Biobehavioral Reviews, 68, 96-110. https://doi.org/10.1016/j.neubiorev.2016.05.002

Gannon, S. (2016). Ordinary atmospheres and minor weather events. Departures in Critical Qualitative Research, 5(4), 79-90. https://doi.org/10.1525/dcqr.2016.5.4.79 
Garay-Barayazarra, G., \& Puri, R. K. (2011). Smelling the monsoon: Senses and traditional weather forecasting knowledge among the KenyahBadeng farmers of Sarawak, Malaysia. Indian Journal of Traditional Knowledge, 10(1), 21-30. https://kar.kent.ac.uk/31520/

Garriott, E. B. (1897). Wind-barometer table. Monthly Weather Review, 25, 204-205. https://doi.org/10.1175/1520-0493(1897)25[204b:WT]2.0.CO;2

Garriott, E. B. (1903). Weather folk-lore and local weather signs. Government Printing Office.

Gearheard, S., Pocernich, M., Stewart, R., Sanguya, J., \& Huntington, H. P. (2010). Linking Inuit knowledge and meteorological station observations to understand changing wind patterns at Clyde River, Nunavut. Climatic Change, 2, 267-294. https://doi.org/10.1007/s10584009-9587-1.

Gendlin, E. T. (1982). Focusing (second edition). Bantam.

Gendlin, E. T. (1997). Experiencing and the creation of meaning: A philosophical and psychological approach to the subjective. Northwestern University Press.

Gibson, J. J. (1979/1986). The ecological approach to visual perception. Psychology Press.

Hall, A. \& Endfield, G, (2016) "Snow Scenes": Exploring the role of memory and place in commemorating extreme winters. Weather, Climate and Society, 8, 5-19, https://doi.org/10.1175/WCAS-D-15-0028.1.

Hall, G. S. (1893). The contents of children's minds upon entering school. Kellogg.

Hamblyn, R. (2017). Clouds: Nature and culture. Reaktion Books. 
Harrison, J., McCoy, C., Bunting-Howarth, K., Sorensen, H., Williams, K., \& Ellis, C. (2014). Evaluation of the National Weather Service impact-based warning tool. Technical Report. https://iiseagrant.org/wp-content/uploads/2019/03/IBW_finalreport.pdf.

Heilig R. 2010. How an iPhone can change the weather. In Proceedings of the 26th Conference on Interactive Information and Processing Systems (IIPS) for Meteorology, Oceanography, and Hydrology, 17-21 January 2010. American Meteorological Society. https://ams.confex.com/ams/pdfpapers/159723.pdf

Hetherington, R. \& Reid R. G. (2010). The climate connection: Climate change and modern human evolution. Cambridge University Press.

Hinds, J., \& Sparks, P. (2008). Engaging with the natural environment: The role of affective connection and identity. Journal of Environmental Psychology, 28(2), 109-120. https://doi.org/10.1016/j.jenvp.2007.11.001

Hoffman, R. R., LaDue, D. S., Mogil, H. M., Roebber, P. J., \& Trafton, J. G. (2017). Minding the weather: How expert forecasters think. MIT Press.

Howard, L. (1865). On the modification of clouds. John Churchill and Sons.

Hubbard, R. (2000). Boater's Bowditch: The small craft American practical navigator. International Marine.

Huppertz, M., \& Schatanek, V. (2017). Mindfulness in nature: 84 nature-oriented exercises \& theoretical foundations. Junfermann Verlag.

Hutmacher, F. (2019). Why is there so much more research on vision than on any other sensory modality? Frontiers in Psychology, 10, 1-12. https://doi.org/10.3389/fpsyg.2019.02246 
Islam, N., \& Want, R. (2014). Smartphones: Past, present, and future. IEEE Pervasive Computing, 13(4), 89-92. https://doi.org/10.1109/MPRV.2014.74.

Jensen, A., Merz, S., Spence, C., \& Frings, C. (2020). Perception it is: Processing level in multisensory selection. Attention, Perception, \& Psychophysics, 82, 1391-1406. https://doi.org/10.3758/s13414-019-01830-4

Kahneman, D. (2011). Thinking, fast and slow. Farrar, Straus, \& Giroux.

Kelly, G. A. (1955). The psychology of personal constructs. Norton.

Kersten, D., Mamassian, P., \& Yuille, A. (2004). Object perception as Bayesian inference. Annual Review of Psychology, 55(1), 271-304. https://doi.org/10.1146/annurev.psych.55.090902.142005

Knox, J. A., Rackley, J. A. Black, A. W., Gensini, V. A., Butler, M., Dunn, C., Gallo, T., Hunter, M. R., Lindsey, L., Phan, M., Scroggs, R., \& Brustad, S. (2013). Tornado debris characteristics and trajectories during the 27 April 2011 super outbreak as determined using social media data. Bulletin of the American Meteorological Society, 94, 1371-1370. https://doi.org/10.1175/BAMS-D-12-00036.1

Korzybski, A. (1958). Science and sanity: An introduction to non-Aristotelian systems and general semantics. (4th Ed.). International Non-Aristotelian Library Publishers.

Lazo, J. K., R. E. Morss, \& Demuth, J. (2009). 300 billion served. Bulletin of the American Meteorological Society, 90, 785-798. https://doi.org/10.1175/2008BAMS2604.1

Lumber, R., Richardson, M., \& Sheffield, D. (2018). The pathways to nature connectedness: A focus group exploration. European Journal of Ecopsychology, 6, 47-68. https://dora.dmu.ac.uk/handle/2086/17231 
Ma, W. \& Thompson, W. F. (2015). Human emotions track changes in the acoustic environment. Proceedings of the National Academies of Science, 112(47), 14563-14568. https://doi.org/10.1073/pnas.1515087112

Mace, W. M. (1977). J. J. Gibson's strategy for perceiving: Ask not what's inside your head, but what your head's inside of. In R. What \& J. Bransford (Eds.). Perceiving, acting and knowing: Towards and ecological psychology (pp. 43-66). Erlbaum.

Markowitsch, H. J., \& Staniloiu, A. (2011). Amygdala in action: Relaying biological and social significance to autobiographical memory. Neuropsychologia, 49(4), 718-733. https://doi.org/10.1016/j.neuropsychologia.2010.10.007

Mayer, F. S., \& Frantz, C. M. (2004). The connectedness to nature scale: A measure of individuals' feeling in community with nature. Journal of Environmental Psychology, 24(4), 503.

Menary, R. (2010). The extended mind. Massachusetts Institute of Technology.

Mergen, B. (1997). Snow in America. Smithsonian Institution Press.

Merrill, A. (1991). Self-differentiation: A day with John and Joyce Weir. (Four videotape set, with transcript). Blue Sky Productions.

Michaels, P. J. (2004). Meltdown: The predictable distortion of global warming by scientists, politicians, and the media. Cato Institute.

Mitrescu, C., Miller, S., Hawkins, J., L’Ecuyer, T., Turk, J., Partain, P. \& Stephens, G. (2008). Near-real-time applications of CloudSat data. Journal of Applied Meteorology and Climatology, 47, 1982-1994, https://doi.org/10.1175/2007JAMC1794.1 
Mix, P. A. (2006) Monumental Legacy: The unique and unheralded contributions of John and Joyce Weir to the human development field. The Journal of Applied Behavioral Science, 43(3), 276-299.

Mogil, H. M. (2020, May 25; originally 2011, exact date unknown). On being an observationalist. http://www.weatherworks.com/lifelong-learning-blog/?p=513

Moraga-Amaro, R. \& Stehberg, J. (2012). The insular cortex and the amygdala: Shared functions and interactions. In B. Ferry (Ed). The amygdala - A discrete multitasking manager. (pp. 231-256). Intech. https://doi.org/10.5772/48495

Moran, A. (2015). Climate change: The facts. Woodsville, NH: Institute of Public Affairs.

Munoz, N. E., \& Blumstein, D. T. (2012). Multisensory perception in uncertain environments. Behavioral Ecology, 3, 457-462. https://doi.org/10.1093/beheco/arr220.

Olander, T. L., \& Velden, C. S. (2007). The advanced Dvorak Technique: Continued development of an objective scheme to estimate tropical cyclone intensity using geostationary infrared satellite imagery. Weather and Forecasting, 22(2), 287-298. https://doi.org/10.1175/waf975.1

Oreskes, N. \& Conway, E. M. (2010). Merchants of doubt: How a handful of scientists obscured the truth on issues from tobacco smoke to global warming. Bloomsbury Publishing.

Pennesi, K., Arokium, J., \& McBean, G. (2012). Integrating local and scientific weather knowledge as a strategy for adaptation to climate change in the Arctic. Mitigation and Adaptation Strategies for Global Change, 17, 897-922.

Perrin, A. \& Anderson, M. (2019). Share of U.S. adults using social media, including Facebook, is mostly unchanged since 2018. Pew Research Center. 
https://www.pewresearch.org/fact-tank/2019/04/10/share-of-u-s-adults-using-social$\underline{\text { media-including-facebook-is-mostly-unchanged-since-2018/ }}$

Peters, J. D. (2016). The marvelous clouds: Toward a philosophy of elemental media. University of Chicago Press.

Phan, M.D., Montz, B. E., Curtis, S. \& Rickenbach, T. M. (2018). Weather on the go: an assessment of smartphone mobile weather application use among college students. Bulletin of the American Meteorological Society, 99, 2245-2257, https://doi.org/10.1175/BAMS-D-18-0020.1

Pretor-Pinney, G. (2006). The cloudspotter's guide: The science, history, and culture of clouds. Penguin.

Pritchard, A. Richardson, M., Sheffield, D., \& McEwan, K. (2020). The relationship between nature connectedness and eudaimonic well-being: A meta-analysis. Journal of Happiness Studies, 21, 1145-1167. https://doi.org/10.1007/s10902-019-00118-6

Polanyi, M. (2015). Personal knowledge: Towards a post-critical philosophy (Enlarged edition). University of Chicago Press.

Putnam, H. (1995). Pragmatism: An open question. Blackwell.

Quade, K. (2007). The traditional meets the emergent: The modernization of T-groups. Preprint. https://www.academia.edu/5726390/The_Traditional_Meets_The_Emergent_The Modernization_of_T_Groups

Racat M. \& Capelli S. (2020) Touching without touching: The paradox of the digital age. In: Haptic sensation and consumer behaviour. Palgrave Pivot. 
Radin, J. (2019). Alternative facts and states of fear: Reality and STS in an age of climate fictions. Minerva: A Review of Science, Learning \& Policy, 57(4), 411-431. https://doi.org/10.1007/s11024-019-09374-5.

Randerson, J. (2018). Weather as medium: Toward a meteorological art. MIT Press.

Reed, E. S. (1996). The necessity of experience. Yale University Press.

Richardson, M., McEwan, K., Maratos, F., \& Sheffield, D. (2016). Joy and calm: How an evolutionary functional model of affect regulation informs positive emotions in nature. Evolutionary Psychological Science, 2, 308-320. https://doi.org/10.1007/s40806-016$\underline{0065-5}$

Richardson, M. Hussain, Z., \& Griffiths, M. D. (2018). Problematic smartphone use, nature connectedness, and anxiety. Journal of Behavioral Addictions, 7(1), 109-116. https://doi.org/10.1556/2006.7.2018.10

Ripberger, J. T., Jenkins-Smith, H., Silva, C. L., Carlson, D. E., \& Henderson, M. (2014). Social media and severe weather: Do tweets provide a valid indicator of public attention to severe weather risk communication? Weather, Climate, and Society, 6(4), 520-530. https://doi.org/10.1175/WCAS-D-13-00028.1

Robertson, M. (2015). An early morning walk: In search of 'the outdoors'. In M. Robertson, R. Lawrence, G. Heath, \& P. Hay (Eds). Experiencing the outdoors: Enhancing strategies for wellbeing (Researching environmental learning; vol. 2). (pp. 1-12). Sense.

Rogers, C. R. (1995). A way of being. Houghton Mifflin.

Roncoli, C., Ingram, K., and Kirshen, P. (2002). Reading the rains: Local knowledge and rainfall forecasting in Burkina Faso. Society and Natural Resources, 15, 409-427. 
Sager, P. C. (2008). Witness consciousness in the development of the individual. Unpublished Master's thesis. Sunbridge College. https://www.threestonestudio.org/witnessconsciousness/

Seim, C., \& Oleksinski, J. (2015, July 9). Why your weather app is ruining your summer. New York Post. https://nypost.com/2015/07/09/your-obsession-with-weather-apps-is$\underline{\text { making-you-crazy/ }}$

Seman, S. (2020). Trusted weather sources and social 'media-rology'. Introductory Meteorology. Retrieved December January $28^{\text {th }}, 2021$ from https://www.eeducation.psu.edu/meteo3/node/2288

Sherman-Morris, K. \& Brown, M. E. (2012). Experiences of the Smithville, Mississippi residents with the 27 April 2011 tornado. National Weather Digest, 36(2), 93-101. http://nwafiles.nwas.org/digest/papers/2012/Vol36No2/Pg093-Sherman-Brown.pdf

Shultz, P. W. (2002). Inclusion with nature: The psychology of human-nature relations. In P. Schmuck \& W. P. Schultz (Eds.), Psychology of sustainable development. (pp. 61-78). Kluwer Academic Publishers.

Silver, A., \& Andrey, J. (2019). Public attention to extreme weather as reflected by social media activity. Journal of Contingencies and Crisis Management, 27(4), 346-358. https://doi.org/10.1111/1468-5973.12265

Smigielski, F. J., \& Mogil, H. M. (1995). A systematic satellite approach for estimating central surface pressures of mid-latitude cold season oceanic cyclones. Tellus, 47A, 876-891.

Spann, J. (2016). The 'social media-rologist' dilemma. AlabamaWx Weather Blog. https://www.alabamawx.com/?p=98058 
Stewart, A. E. (2007). Linguistic dimensions of weather and climate perception. International Journal of Biometeorology, 52(1), 57-67. https://doi.org/10.1007/s00484-007-0101-z

Stewart, A. E. (2009). Minding the weather: The measurement of weather salience. Bulletin of the American Meteorological Society, 90, 1833-1841. https://doi.org/10.1175/2009BAMS2794.1

Stewart, A. E., \& Blau, J. J. C. (2019). Weather as ecological events. Ecological Psychology, 31(2), 107-126. https://doi.org/10.1080/10407413.2018.1552496

Stewart, A. E., \& Oh, J. (2019). Weather and climate as events: Contributions to the public idea of climate change. International Journal of Big Data Mining for Global Warming, 1(2). https://doi.org/10.1142/S2630534819500050

Stewart, A. E., Lazo, J. Morss, R. \& Demuth, J. (2012). The relationship of weather salience with the perceptions, uses, and values of weather information in a nationwide sample of the United States. Weather, Climate, \& Society, 4, 172-189. http://dx.doi.org/10.1175/WCAS-D-11-00033.1

Stith, J. L., Baumgardner, D., Haggerty, J., Hardesty, R. M.,Lee, W., Lenschow, D., Pilewskie, P., Smith, P. L., Steiner, M \& Vömel, H. (2018). 100 Years of progress in atmospheric observing systems. Meteorological Monographs, 59, 2.1-2.55. https://doi.org/10.1175/AMSMONOGRAPHS-D-18-0006.1

Stokes, C. \& Senkbeil, J.C. (2017), Facebook and Twitter, communication and shelter, and the 2011 Tuscaloosa tornado. Disasters, 41, 194-208. https://doi.org/10.1111/disa.12192

Thurlow, C. \& Poff, M. (2013). Text messaging. In S. Herring, D. Stein, \& T. Virtanen (Eds). Pragmatics of Computer-Mediated Communication. (pp. 163-189). de Gruyter. 
Toth, Z. (1989). Long-range weather forecasting using an analog approach. Journal of Climate, 2, 594-607. https://doi.org/10.1175/1520-0442(1989)002<0594:LRWFUA>2.0.CO;2

Tsakiris, M. (2017). The multisensory basis of self: From body to identity to others. Quarterly Journal of Experimental Psychology, 70, 597-609. https://doi.org/10.1080/17470218.2016.1181768.

Tuan, Y. (1974). Topophilia: A study of environmental perception, attitudes, and values. Prentice-Hall.

Valenčius C. B. (2002) The health of the country: How American settlers understood themselves and their land. Basic Books.

Vannini, P., Waskul, D., Gottschalk, S. \& Ellis-Newstead, T. (2012). Making sense of the weather: Dwelling and weathering on Canada's rain coast. Space and Culture, 15(4), $361-380$.

Velden, C., Harper, B., Wells, F., Beven, J. L., Zehr, R., Olander, T., Mayfield, M., Guard, C. C., Lander, M., Edson, R., \& Avila, L., Burton, A., Turk, M., Kikuchim A., Christian, A., Caroff, P., \& McCrone, P. (2006). The Dvorak tropical cyclone intensity estimation technique: A satellite-based method that has endured for over 30 years. Bulletin of the American Meteorological Society, 87(9), 1195-1210. https://doi.org/10.1175/bams-87-9$\underline{1195}$

Vos, S. C., Sutton, J., Yu, Y., Renshaw, S. L., Olson, M. K., Gibson, C. B., \& Butts, C. T. (2018). Retweeting risk communication: The role of threat and efficacy. Risk Analysis, 38(12), 2580-2598. https://doi.org/10.1111/risa.13140 
Wallace, M. T., Woynaroski, T. G., \& Stevenson, R. A. (2020). Multisensory integration as a window into orderly and disrupted cognition and communication. Annual Review of Psychology, 71, 193-219. https://doi.org/10.1146/annurev-psych-010419-051112.

Willander, J., \& Larsson, M. (2007). Olfaction and emotion: The case of autobiographical memory. Memory \& Cognition, 35(7), 1659-1663. https://doi-org/10.3758/BF03193499

Wurman, J., Kosiba, K. \& Robinson, P. (2013). In situ, doppler radar, and video observations of the interior structure of a tornado and the wind-damage relationship. Bulletin of the American Meteorological Society, 94, 835-846, https://doi.org/10.1175/BAMS-D-12$\underline{00114.1}$

Yoder-Bontrager, D., Trainor, J. E., \& Swenson, M. (2017). Giving attention: Reflections on severe weather warnings and alerts on mobile devices. International Journal of Mass Emergencies \& Disasters, 35(3), 169-190.

Zabini, F. (2016). Mobile weather apps or the illusion of certainty. Meteorological Applications, 4, 663-670. https://doi.org/10.1002/met.1589

Zhang, J. W., Howell, R. T., \& Iyer, R. (2014). Engagement with natural beauty moderates the positive relation between connectedness with nature and psychological well-being. Journal of Environmental Psychology, 38, 55-63. https://doi.org/10.1016/j.jenvp.2013.12.013

Zhang, J. W., Piff, P. K., Iyer, R., Koleva, S., \& Keltner, D. (2014). An occasion for unselfin: Beautiful nature leads to prosociality. Journal of Environmental Psychology, 37, 61-72. https://doi.org/10.1016/j.jenvp.2013.11.008 